See discussions, stats, and author profiles for this publication at: https://www.researchgate.net/publication/332517909

Less "human" than us: dehumanisation as a psychological barrier to the integration of migrants

Chapter · April 2019

DOI: 10.1515/9783110628746-008

CITATIONS

0

2 authors:

Niamh McLoughlin

University of Kent

10 PUBLICATIONS 64 CITATIONS

SEE PROFILE
READS

94

Harriet Over

The University of York

70 PUBLICATIONS 1,780 CITATIONS

SEE PROFILE 


\title{
Less "human" than us: dehumanisation as a psychological barrier to the integration of migrants
}

\begin{abstract}
Prejudice and discriminatory behaviour remain significant barriers to positive intergroup relations. In a time in which global migration rates are at their highest (and continue to rise), recent emphasis has been placed on the negative perceptions of certain immigrant and refugee group members in Western media and political discourse. A prominent feature of these debates involves the perceived "humanness" of migrant individuals. The tendency to view culturally dissimilar others as less human compared to one's own cultural group is not a novel social phenomenon however. In this chapter, we draw from the fields of philosophy, social and developmental psychology to examine the nature of dehumanisation in the context of migration. Through understanding the psychological processes by which dehumanising perceptions are acquired and expressed, this research ultimately hopes to inform strategies to foster the inclusion of newcomers within their host countries.
\end{abstract}

\section{Introduction}

Concerns over the perception and treatment of immigrant and refugee group members have been recently highlighted in Western public discourse. This particular emphasis in debate has followed a number of significant political and social-cultural shifts - namely, the mass migration of those seeking refuge in Europe from conflicts in Syria and the rise of populism across Western societies. One of the most striking aspects of these debates involves the perceived "humanness" of migrant individuals (Bruneau/Kteily/Laustsen 2017). Their humanity has often been questioned in the public domain of their prospective host nations, whether that be the derogatory language chosen to describe their arrival or the crude visual depictions of their plight (Esses/Medianu/Lawson 2013; Bleiker et al. 2013). As well as potentially contributing to human rights violations (e.g., the separation and detainment of families at the southern US border), the assumption that certain social groups are less human than others in some respect could be a substantial challenge for their successful integration within host communities. The harmful phenomenon of "dehumanisation" has been a topic of im- 
port to philosophers and social psychologists, and most recently for researchers interested in the origins of prejudice in young children (McLoughlin/Over 2018).

In this chapter, we summarize psychological research on dehumanisation in the context of migration with adults and what this means for their willingness to engage in moral action. We then discuss some of the potential psychological mechanisms (e.g., perceived threat) that could clarify why migrant groups are particularly vulnerable to dehumanising perceptions. Lastly, we argue for the importance of examining the development of dehumanising attitudes towards migrants among children in order to ultimately overcome this intergroup barrier.

\section{Dehumanisation and moral responsibility}

Early psychological theorists first studied the phenomenon of dehumanisation in an effort to explain extreme intergroup violence witnessed during the twentieth century (Bar-Tal 1989; Kelman 1973; Opotow 1990). In his theory of moral disengagement, Albert Bandura posits that viewing other people not as individuals with 'feelings, hopes, concerns, but as subhuman objects...as mindless "savages”, “gooks”, “satanic fiends”...and other bestial creatures' is a core psychological process for weakening moral inhibitions against cruel behaviour (Bandura et al. 1996). This explicit denial of humanness is typically seen in the perceptions of outgroup members (persons who have a different social identity to one's own, for example, different race or national affiliation) and is easily recognizable in public rhetoric regarding migrants. Established politicians in Europe have warned local constituents of a 'swarm' or a 'flood' due to rising migration rates (Shah 2015) and have even referred to this demographic as 'wild beasts' and 'human trash' (Bruneau/Kteily/Laustsen 2017). In addition to the very explicit dehumanisation of migrants, it has been further suggested that more implicit dehumanising beliefs play a role in perceived moral responsibility for members of these groups. In this section, we explore the research in social psychology which has investigated the harmful consequences that both blatant and more subtle forms of dehumanisation have for moral engagement among adults. Specifically, this work has focused on adults' endorsements of the cultural inclusion of migrants, their general concern for migrant individuals, and their prosocial intentions towards minorities in need.

Researchers from several different traditions have characterized outgroup dehumanisation in terms of overt references to animals, primates, and other more lowly biological entities (Smith 2012; Goff et al. 2008; O’Brien 2003). In an advance on the study of blatant dehumanisation across contemporary societies, Kteily and colleagues (Kteily et al. 2015) developed a measure that assesses 
adult perceptions about how "evolved" or civilized social groups appear to be. For these studies, participants were asked to make scalar judgements using the popular graphic of the "Ascent of Man" (i.e., five silhouettes representing important physiological steps in the evolution of humans). They found that participants' ratings of different outgroups on this scale, when compared with ratings of people from their own social group (ingroup), were consistently linked to their endorsement of discriminatory attitudes (especially in the case of persecuted minority outgroups). For example, the perception that Arab ethnic outgroups are 'less evolved' than Americans predicted increased agreement with controlling the migration of Arab individuals and fewer expressions of compassion when an Arab person experienced an injustice. Similarly, these dehumanising beliefs predicted British participants' support for anti-Muslim policies and Hungarian adults' reluctance to provide financial aid for the integration of the Roma community into the larger society.

This measure has also been applied to study the current dynamics of rising migration rates in Europe. The results of a large-scale study conducted in the Czech Republic, Hungary, Greece, and Spain showed that dehumanising perceptions of Muslim refugees (again, that they are less 'evolved' than the ingroup) were uniquely associated with less willingness to engage in affirmative action for asylum seekers (Bruneau/Kteily/Laustsen 2017). This association was stronger in the Eastern European countries which the authors attribute in part to the higher frequency of explicit anti-migrant rhetoric in the political domains of these two nations.

Apart from the research outlined above, social psychologists have tended to focus more on capturing everyday instances of dehumanising thought in their experimental research (Haslam/Loughnan 2014). This body of work has shown that, across various cultural settings, adults attribute fewer traits uniquely linked to 'humanness', including intelligence, openness, and cultural refinement, to social outgroups (Vaes et al. 2012; Haslam et al. 2008). One influential account developed by Leyens et al. (2000) suggests that outgroup members are perceived to be less capable of the complex emotional experiences thought to be uniquely human, like the ability to feel proud or remorseful. This bias in emotion perception has been coined outgroup 'infra-humanisation' in social psychology (Leyens 2009).

Building on this theoretical perspective, researchers have provided experimental evidence that speaks to how implicit attributions of humanness can shape intergroup interactions within the context of migration. For instance, Leyens, Demoulin, Gaunt, Vaes and Paladino (2007) found that the belief Muslim refugees experience fewer complex emotions (infra-humanisation) was associated with the objection of their migration into European territory. In a related 
study, Portuguese participants demonstrated greater opposition to Turkey joining the European Union after reading a description which implied that people from this culture more readily express basic emotions over uniquely human emotions (Pereira/Vala/Leyens 2009). More generally, other research has revealed that attributing fewer human-like capacities to others can reduce individual contributions to humanitarian aid in the aftermath of natural disasters (Cuddy/ Rock/Norton 2007; Andrighetto 2014).

Overall, these studies are compelling evidence that thinking of migrant groups as not entirely human can have a direct negative influence on the host society's understanding of their social and moral obligations towards them. The harmful effects of dehumanisation are observed even when intergroup distinctions are based on more subtle differences in a person's ability to experience and express human feeling. Needless to say, it is not only migrants that experience the effects of dehumanisation. This phenomenon is clearly evident in group relations between and within different societies, for example, amid the historically rooted racial tensions in the United States (Goff et al. 2008). Yet, some of the intergroup and psychological features that characterize periods of mass migration might make immigrants and refugee groups especially vulnerable to dehumanising perceptions.

\section{Psychological mechanisms of migrant dehumanisation}

Previous research has delineated several psychological processes that contribute to the derogation of migrants: incoming migrant groups are perceived to represent a threat to the host nation; migrants are typically part of a group associated with lower status; and migrants originate from cultural backgrounds that are considered very different, and perhaps impenetrable, to the ingroup (Chavez 2001; Fiske et al. 2002; Haslam et al. 2006).

\subsection{Perceived threat}

Many of the public representations of migrants in Western countries highlight the potential dangers their arrival can pose to the host nations (Esses/Medianu/Lawson 2013). Analyses of media content have revealed that common descriptions of migrant groups involve claims that they are carriers of contagion or disease, that they aim to 'cheat' the system and become dependent on the 
state, and that they are likely to commit violent criminal acts (Cisneros 2008; Louis 2006; Vaes 2017). Comparing outgroup members to threatening entities in this way encourages certain inferences about their character traits (Tirrell 2012) and can licence severe behavioural responses - that they must be monitored, detained, or, in the most extreme cases, eliminated for the benefit of the general public (Smith 2012).

Experimental research has revealed that each of these depictions plays a role in facilitating the dehumanising percept. For example, portraying migrants as potential contaminants increased hostile attitudes (via emotive reactions such as disgust and contempt) among US and Canadian participants (Esses/Medianu/Lawson 2013; Utych 2017). Priming the idea that incoming asylum seekers are attempting to undercut host systems was also highly correlated to the belief they inherently lack moral sensibility (Esses et al. 2008) - a belief which has been conceptualized as a more indirect form of dehumanisation (Schwartz/ Struch 1989). In addition, reading editorials which imply that certain migrant groups belong to a terrorist organization elicited faster implicit associations between migrants and animalistic concepts (Esses/Medianu/Lawson 2013). Indeed, Kteily et al. (2015) observed a spike in blatant dehumanising ratings of Arab individuals in the aftermath of real-life terrorist situations, such as the Boston Marathon bombing in 2013. Thus it seems that, beyond the harmful impact of messages disseminated by the media, more general states of psychological threat can facilitate dehumanising biases.

\subsection{Perceived status}

The harsh circumstances in which many migrants find themselves might make them more vulnerable to perceptions of low status in the host society. Philosophers and social psychologists have reasoned that perceived status differences might be integral to the concept of dehumanisation. In his philosophical account of explicit dehumanisation, Smith (2012) notes that targeted minority group members throughout history were not only considered less human than members of the dominant cultural group, but less than human. Bruneau et al. (2017) also suggest that status plays an important role in the belief that migrant groups are 'less evolved' than other social groups in Europe. Across their studies, participants tended to think of high-status outgroups (e.g., German or Swedish) as equally human to their own group. Moreover, individual differences in relative support for the hierarchical structure of group relations has been related to dehumanising perceptions of migrants (Costello/Hodson 2011; Esses 2008; Haslam/ Loughnan 2014). 
The literature investigating the impact of status differences for more subtle attributions of humanity is more mixed (Vaeset al. 2012). While some researchers argue that both high and low status groups assign fewer uniquely human traits to outgroup members (Leyens 2009), others suggest the social groups that are at least judged as less competent (a distinct but closely related construct to status (Fiske et al. 2002)) are more likely to be infra-humanised (Vaes/Paladino 2009).

\subsection{Perceived 'fundamental' differences}

It is often the case that migrant groups possess myriad cultural characteristics that differ from the population of the host nation, including their first spoken language, their ethnic background, and/or their religious values (Algan et al. 2012). These intercultural differences could highlight the psychological boundaries between groups and, under specific conditions, may foster the perspective that members of migrant groups represent fundamentally different 'kinds' of people (Prentice/Miller 2007; Rhodes/Mandalaywala 2017). A number of prominent theorists have proposed that the belief that outgroup members are inherently different from the ingroup, and that their unfamiliar behaviour and traits are explained by a fixed underlying quality or 'essence', could be involved in dehumanising thought (Smith 2014; Leyens et al. 2001). Simply put, social outgroup members are often denied the innate 'humanness' that is more automatically attributed to perceived similar others.

Social psychological research suggests that less knowledge of and contact with migrant groups contribute to greater perceived intergroup differences and can promote dehumanising beliefs. For instance, Capozza et al. (2013) found that Italian adults' lower reports of interactions with migrants predicted increases in the salience of intergroup boundaries, which was ultimately associated with fewer attributions of human traits. In a similar vein, it was observed that, across several cultural contexts, less awareness and understanding of another group's cultural viewpoint was linked to decreases in their perceived capacity for complex emotion (Rodríguez-Pérez et al. 2011). Bruneau et al. (2017) also implied that the finding that blatant dehumanising Muslim perceptions were less severe among participants in Greece may be because of the increased proximity between host and Muslim refugee communities in this setting. 


\section{The development of dehumanising perceptions}

Given that the current generation is witness to some of the highest migration rates in modern times (International Organization for Migration 2011), it is important to also direct attention to the development of potentially derogatory migrant attitudes in young children. Developmental researchers have illustrated how the psychological features of stereotyping, prejudice, and discrimination are present from a young age (Over/McCall 2018). From about the age of five, children profess explicit liking for members of their own groups and are more concerned with helping and staying loyal to socially similar others (Kinzler/Dupoux/Spelke 2007; Over 2018; Dunham/Degner 2010). Recent efforts have strived to extend this work to measure the social origins of dehumanisation. The research we now outline has not investigated the development of dehumanising migrant perceptions per se, to our knowledge this topic has been unexplored to date, but it rather has measured variations in human-like attributions across parallel social divisions (i.e., racial, ethnic, national).

As in research with adults, previous studies have demonstrated how children may conceive of in- and outgroup members differently with regards to the traits thought to distinguish humans from animals. Costello and Hodson (2014) revealed that six- to ten-year-old White children attributed Black children with fewer uniquely human capacities (e.g., curiosity, guilt) in the United States, and Chas et al. (2018a) found that ten- to thirteen-year-olds were quicker to implicitly associate animalistic words, like 'wild', 'creature' and 'pet', with Arab names than with (ingroup) Spanish names. Other work has examined the development of dehumanising biases on the basis of nationality. Scottish children, aged six to ten, judged members of a national outgroup football team as experiencing less intense second-order emotions than members of their own national team (Martin/Bennett/Murray 2008). Focusing on perceptions of physical humanness, our research has shown that six-year-old British children rated ambiguously animate (doll-human) faces to be less human when they were told they originated from a country far away from their own town (McLoughlin/Tipper/ Over 2017).

More broadly related to this harmful phenomenon, Dore and colleagues (Dore et al. 2014; Dore et al. 2017) found that the belief that Black children feel less pain than do other White children gradually emerges between the ages of five and ten among White participants in the US. Chas et al. (2018b) have also explored the effect that group membership has for children's understanding of others' pain. They were interested in judgements of both physical 
and 'social pain', such as personal distress in response to social rejection. Their results revealed that Spanish children (nine- to thirteen-year-olds) expected peers with typical Arab names to experience a lower level of socially driven negative pain. (They did not find any differences in children's judgements of in- and outgroup members' experiences of physical pain in this culture however.) Our own research has shown that children may reason about the internal experiences of social groups differently: British five- and six-year-olds were less likely to spontaneously refer to the mental states (i.e., thoughts, desires, emotions) of agents who spoke a different language and lived in a different country to them (McLoughlin/Over 2017).

The convergence of this evidence suggests that children can hold dehumanising views of perceived culturally distant others, but also that dehumanisation may be at least partially socially learned. For example, we observed that British five-year-olds perceived equal humanness across in- and outgroup faces, whereas there was a significant decrease in outgroup humanness ratings in the older children (McLoughlin/Tipper/ Over 2017). Furthermore, ten-year-old White children in the United States perceived that racial outgroup members experience less physical pain than their own racial group, whereas this bias in the perception of physical pain was not evident among similarly aged children in Spain. Future studies need to examine how dehumanising beliefs might be culturally transmitted to young observers from parents, the media, and other influential sources and to determine whether this transmission process relies on certain psychological biases (e.g., perceived fundamental distinctions between groups) (McLoughlin/Over 2018).

Another way that developmental research could be useful in the study of this social problem is by providing insight into how dehumanising biases can be overcome before they become deeply entrenched in social interactions and perception. Reducing the tendency to dehumanise outgroup members has received relatively little research attention in work with adults, especially when it comes to improving the perceptions of immigrants and refugees. Individual variations in contact with and knowledge of migrant group members, as well as higher levels of trait empathy (Bruneau/Kteily/Laustsen 2017), are related to increases in human attributions. One strategy that has been successful in increasing the perceived 'humanness' of outgroups in other contexts involves priming a shared social identity beyond that of the current group division. In these experimental studies, reminding adults of the broader national or ethnic identity that different local groups have in common, or emphasizing that outgroup individuals also belong in a superordinate 'human' category, had benefits for humanness perceptions (Gaunt 2009; Albarello/Rubini 2012). 
Research in developmental psychology has highlighted some promising routes for combatting dehumanising attitudes towards migrants. Complimentary to findings with adults, exposing children and adolescents to indirect contact with migrants, even just by reading about positive intergroup interactions in a storybook, can lead to increases in social preference for a member of this group (Cameron et al. 2006; Vezzali/Stathi/Giovannini 2012). Looking more specifically at dehumanising biases, Vezzali et al. (2012) have revealed that asking nine-year-olds to imagine interacting with an immigrant peer (over a threeweek period and in different environments) had a positive indirect influence on the extent to which they attributed uniquely human emotions to them.

We recently sought to measure whether encouraging children to reflect on the mental lives of migrant group members - an important aspect of folk conceptions of humanity (Waytz/Epley/Cacioppo 2010) - had a positive effect on their moral obligations towards another migrant individual (McLoughlin/Over forthcoming). In this study, five- and six-year-old British participants were either prompted to talk about the thoughts and feelings (e.g., "What are they thinking about?") or the actions (e.g., "What are they doing?") of children who were described as migrants to the UK. We found that the children asked to discuss the mental states of migrant peers in everyday situations were more willing to share resources with another migrant child who was victim to a minor transgression (i.e., one of their belongings were stolen). Hence, thinking more deeply about the behaviour of a migrant group had a significant positive impact on children's prosocial behaviour over and above simply talking about the actions of this group more generally. Future work should continue to build on these experimental approaches in order to identify the optimal intergroup training for improving migrant perceptions at a young age.

To conclude, dehumanisation is a pervasive social problem and is closely connected to the negative treatment and neglect of incoming immigrant and refugee groups. In this chapter, we have outlined research investigating the dehumanising perceptions of migrants from a variety of perspectives in philosophy, social and developmental psychology. This work has often converged to identify some of the psychological factors which may facilitate or impede the tendency to think of perceived culturally dissimilar others as 'less human', but has also highlighted the multifaceted nature of this harmful phenomenon. We hope that this review will ultimately be informative for strategies to enhance the inclusion of newcomers within their host nations. 


\section{Bibliography}

Albarello, F./Rubini, M. (2012): Reducing Dehumanisation Outcomes Towards Blacks: The Role ofMmultiple Categorisation and of Human Identity. In: European Journal of Social Psychology 42(7), 875-882. doi: 10.1002/ejsp.1902.

Algan, Y./Bisin, A., A./Manning, A./Verdier, T. (2012): Cultural Integration of Immigrants in Europe. Oxford: Oxford University Press.

Andrighetto, L./Baldissarri, C./Lattanzio, S./Loughnan, S./Volpato, C. (2014): Human-itarian Aid? Two Forms of Dehumanization and Willingness to Help after Natural Disasters. In: Br J Soc Psychol 53(3), 573-584. doi: 10.1111/bjso.12066.

Bandura, A./Barbaranelli, C./Caprara, G. V./Pastorelli, C. (1996): Mechanisms of Moral Disengagement in the Exercise of Moral Agency. In: Journal of Personality and Social Psychology 71(2), 364-374. doi: 10.1037/0022-3514.71.2.364.

Bar-Tal, D. (1989): Delegitimization: The extreme case of stereotyping and prejudice. In: Daniel Bar-Tal, et al. (eds.): Stereotyping and Prejudice: Changing Conceptions. New York: Springer New York, 169-182.

Bleiker, R. Campbell, D. Hutchison, E. Nicholson, X. (2013): The Visual Dehumanisation of Refugees. In: Australian Journal of Political Science 48(4), 398-416. doi: 10.1080/10361146.2013.840769.

Bruneau, E./Kteily, N./Laustsen, L. (2017): The Unique Effects of Blatant Dehumanization on Attitudes and Behavior Towards Muslim Refugees during the European 'Refugee Crisis' across Four Countries. In: European Journal of Social Psychology 48(5), 645-662. doi: 10.1002/ejsp.2357.

Cameron, L./Rutland, A./Brown, R./Douch, R. (2006): Changing Children's Intergroup Attitudes toward Refugees: Testing Different Models of Extended Contact. In: Child Development 77(5), 1208-19. doi: 10.1111/j.1467-8624.2006.00929.x.

Capozza, D./Trifiletti, E./Vezzali, L./Favara, I. (2013): Can Intergroup Contact Improve Humanity Attributions? In: International Journal of Psychology 48(4), 527-541. doi: 10.1080/00207594.2012.688132.

Chas, A./Betancor, V./Delgado, N./Rodríguez-Pérez, A. (2018a): Children Consider their Own Groups to be More Human than Other Social Groups: Evidence from Indirect and Direct Measures. In: Social Psychology 49(3), 125-134.

Chas Villar, A./Betancor Rodriguez, V./Delgado Rodriguez, N./Rodriguez-Perez, A. (2018b): They Do Not Suffer Like Us: The Differential Attribution of Social Pain as a Dehumanization Criterion in Children. In: Psicothema 30(2), 207-211. doi: 10.7334/psicothema2017.236.

Chavez, L. R. (2001): Covering Immigration: Popular Images and the Politics of a Nation. Berkeley: University of California Press.

Cisneros, J. D. (2008): Contaminated Communities: The Metaphor of “Immigrant as pollutant' in Media Representations of Immigration. In: Rhetoric and Public Affairs 11(4), 569-601.

Costello, K./Hodson, G. (2011): Social Dominance-Based Threat Reactions to Immigrants in Need of Assistance. European Journal of Social Psychology 41(2), 220-231. doi: 10.1002/ejsp.769.

Costello, K./Hodson, G. (2014): Explaining Dehumanization among Children: The Interspecies Model of Prejudice. In: British Journal of Social Psychology 53(1), 175-197. doi: 10.1111/bjso.12016. 
Cuddy, A. J. C./Rock, M. S./Norton, M. I. (2007): Aid in the Aftermath of Hurricane Katrina: Inferences of Secondary Emotions and Intergroup Helping. In: Group Processes \& Intergroup Relations 10(1), 107-118. doi: 10.1177/1368430207071344.

Dore, R. A./Hoffman, K. M./Lillard, A. S./Trawalter, S. (2014): Children's Racial Bias in Perceptions of Others' Pain. In: British Journal of Developmental Psychology 32(2), 218-231. doi: 10.1111/bjdp.12038.

Dore, R. A./Hoffman, K. M./Lillard, A. S./Trawalter, S. (2017): Developing Cognitions about Race: White 5- to 10-year-olds' Perceptions of Hardship and Pain. In: European Journal of Social Psychology 48(2), 0121-0132. doi: 10.1002/ejsp.2323.

Dunham, Y./Degner, J. (2010): Origins of Intergroup Bias: Developmental and Social Cognitive Research on Intergroup Attitudes. In: European Journal of Social Psychology 40(4), 563-568. doi: 10.1002/ejsp.758.

Esses, V. M./Medianu, S./Lawson, A. S. (2013): Uncertainty, Threat, and the Role of the Media in Promoting the Dehumanization of Immigrants and Refugees. In: Journal of Social Issues 69(3), 518-536. doi: 10.1111/josi.12027.

Esses, V. M./Veenvliet, S./Hodson, G./Mihic, L. (2008): Justice, Morality, and the Dehumanization of Refugees. In: Social Justice Research 21, 4-25.

Fiske, S. T./Cuddy, A. J./Glick, P./Xu, J. (2002): A Model of (often Mixed) Stereotype Content: Competence and Warmth Respectively Follow from Perceived Status and Competition. In: Journal of Personality and Social Psychology 82(6), 878-902.

Gaunt, R. (2009): Superordinate Categorization as a Moderator of Mutual Infrahumanization. In: Group Processes \& Intergroup Relations 12(6), 731-746. doi: $10.1177 / 1368430209343297$.

Goff, P. A./Eberhardt, J. L./Williams, M. J./Jackson, M. C. (2008): Not Yet Human: Implicit Knowledge, Historical Dehumanization, and Contemporary Consequences. In: Journal of Personality and Social Psychology 94(2), 292-306. doi: 10.1037/0022-3514.94.2.292.

Haslam, N./Kashima, Y./Loughnan, S./Shi, J./Suitner, C. (2008): Subhuman, Inhuman, and Superhuman: Contrasting Humans with Nonhumans in Three Cultures. In: Social Cognition 26(2), 248-258. doi: 10.1521/soco.2008.26.2.248.

Haslam, N./Loughnan, S. (2014): Dehumanization and Infrahumanization. In: Annual Review of Psychology 65(1), 399-423. doi: 10.1146/annurev-psych-010213-115045.

International Organization for Migration (2011): About Migration. Retrieved from http://www. iom.int/jahia/Jahia/about-migration/lang/en.

Kelman, H. G. (1973): Violence Without Moral Restraint: Reflections on the Dehumanization of Victims and Victimizers. In: Journal of Social Issues 29(4), 25-61. doi: 10.1111/j.1540-4560.1973.tb00102.x.

Kinzler, K. D./Dupoux, E./Spelke, E. S. (2007): The Native Language of Social Cognition. In: Proceedings of the National Academy of Sciences USA 104(30), 12577-80. doi: 10.1073/pnas.0705345104.

Kteily, N./Bruneau, E./Waytz, A./Cotterill, S. (2015): The Ascent of Man: Theoretical and Empirical Evidence for Blatant Dehumanization. In: Journal of Personality and Social Psychology 109(5), 901-931. doi: 10.1037/pspp0000048.

Leyens, J. P. (2009): Retrospective and Prospective Thoughts about Infrahumanization. In: Group Processes \& Intergroup Relations 12(6), 807-817. doi: $10.1177 / 1368430209347330$. 
Leyens, J. P./Demoulin, S./Vaes, J./Gaunt, R./Paladino, M. P. (2007): Infra-humanization: The wall of group differences. In: Social Issues and Policy Review 1(1), 139-172. doi: 10.1111/j.1751-2409.2007.00006.x.

Leyens, J. P./Paladino, P. M./Rodriguez-Torres, R./Vaes, J./Demoulin, S./Rodriguez-Perez, A./Gaunt, R. (2000): The Emotional Side of Prejudice: The Attribution of Secondary Emotions to Ingroups and Outgroups. In: Personality and Social Psychology Review 4(2), 186-197. doi: $10.1207 /$ s15327957pspr0402_06.

Leyens, J. P./Rodriguez-Perez, A./Rodriguez-Torres, R./Gaunt, R./Paladino, M.-P./Vaes, J./Demoulin, S. (2001): Psychological Essentialism and the Differential Attribution of Uniquely Human Emotions to Ingroups and Outgroups. In: European Journal of Social Psychology 31(4), 395 - 411. doi: 10.1002/ejsp.50.

Louis, W. R./Duck, J. M./Terry, D. J./Schuller, R. A./Lalonde, R. N. (2006): Why Do Citizens Want to Keep Refugees Out? Threats, Fairness and Hostile Norms in the Treatment of Asylum Seekers. In: European Journal of Social Psychology 37(1), 53-73. doi: 10.1002/ejsp.329.

Martin, J./Bennett, M./Murray, W. S. (2008): A Developmental Study of the Infrahumanization Hypothesis. In: British Journal of Developmental Psychology 26(2), 153-62. doi: 10.1348/026151007X216261.

McLoughlin, N./Over, H. (2017): Young Children Are More Likely to Spontaneously Attribute Mental States to Members of their Own Group. In: Psychological Science 28(10). doi: $10.1177 / 0956797617710724$.

McLoughlin, N/Over, H. (2018): The Developmental Origins of Dehumanization. In: Advances in Child Development and Behavior 54, 153-178. doi: 10.1016/bs.acdb.2017.10.006.

McLoughlin, N./Over, H. (forthcoming): Encouraging Children to Mentalise about a Perceived Outgroup Increases Empathic Helping towards Them. Developmental Science.

McLoughlin, N./Tipper, S. P./Over, H. (2017): Young Children Perceive Less Humanness in Outgroup Faces. In: Developmental Science 21(2), e12539. doi: 10.1111/desc.12539.

O’Brien, G. V. (2003): Indigestible Food, Conquering Hordes, and Waste Materials: Metaphors of Immigrants and the Early Immigration Restriction Debate in the United States. In: Metaphor and Symbol 18(1), 33-47. doi: 10.1207/S15327868MS1801_3.

Opotow, S. (1990): Moral Exclusion and Injustice: An Introduction. In: Journal of Social Issues 46(1), 1-20. doi: 10.1111/j.1540-4560.1990.tb00268.x.

Over, H. (2018). The Influence of Group Membership on Young Children's Prosocial Behaviour. In: Current Opinion in Psychology. doi: 10.1016/j.copsyc.2017.08.005.

Over, H./McCall, C. (2018): Becoming Us and Them: Social Learning and Intergroup Bias. In: Social and Personality Psychology Compass 12(4), e12384. doi: 10.1111/spc3.12384.

Pereira, C./Vala, J./Leyens, J. P. (2009): From Infra-humanization to Discrimination: The Mediation of Symbolic Threat Needs Egalitarian Norms. In: Journal of Experimental Social Psychology 45(2), 336-344. doi: 10.1016/j.jesp.2008.10.010.

Prentice, D. A./Miller, D. T. (2007): Psychological Essentialism of Human Categories. In: Current Directions in Psychological Science 16(4), 202-206. doi: 10.1111/j.1467-8721.2007.00504.x.

Rhodes, M./Mandalaywala, T. M. (2017): The Development and Developmental Consequences of Social Essentialism. In: Wiley Interdiscip Reviews: Cognitive Science 8(4), e1437. doi: 10.1002/wcs.1437. 
Rodríguez-Pérez, A./Delgado Rodríguez, N./Betancor Rodríguez, V./Leyens, J. P./Vaes, J. (2011): Infra-humanization of Outgroups throughout the World: The Role of Similarity, Intergroup Friendship, Knowledge of the Outgroup, and Status. In: Anales de Psicología/Annals of Psychology 27(3), 9.

Schwartz, S. H./Struch, N. (1989): Values, Stereotypes, and Intergroup Antagonism. In: Daniel Bar-Tal, et al. (eds.): Stereotyping and Prejudice: Changing Conceptions. New York: Springer New York, 151-67.

Shah, V. (2015): Swarms and Marauders: The Dehumanising Language of Migration. In: Cafébabel. Retreived from http://www.cafebabel.co.uk/culture/article/swarms-and-ma rauders-the-dehumanising-language-of-migration.html.

Smith, D. L. (2012): Less than Human: Why We Demean, Enslave, and Exterminate Others. New York: Macmillan.

Smith, D. L. (2014): Dehumanization, Essentialism, and Moral Psychology. In: Philosophy Compass 9(11), $814-824$.

Tirrell, L. (2012): Genocidal Language Games. In: I. Maitra and M. K. McGowan (eds.): Speech and Harm: Controversies Over Free Speech. Oxford: Oxford University Press, 174-221.

Utych, S. M. (2017): How Dehumanization Influences Attitudes toward Immigrants. In: Political Research Quarterly 71(2), 440-452. doi: 10.1177/1065912917744897.

Vaes, J./Latrofa, M./Suitner, C./Arcuri, L. (2017): They Are All Armed and Dangerous! In: Journal of Media Psychology 1-12. doi: 10.1027/1864-1105/a000216.

Vaes, J./Leyens, J. P./Paladino, M. P./Miranda, M. P. (2012): We Are Human, They Are Not: Driving Forces behind Outgroup Dehumanisation and the Humanisation of the Ingroup. In: European Review of Social Psychology 23(1), 64-106. doi: 10.1080/10463283.2012.665250.

Vaes, J./Paladino, M. P. (2009):The Uniquely Human Content of Stereotypes. In: Group Processes \& Intergroup Relations 13(1), 23 -39. doi: 10.1177/1368430209347331.

Vezzali, L./Capozza, D./Stathi, S./Giovannini, D. (2012): Increasing Outgroup Trust, Reducing Infrahumanization, and Enhancing Future Contact Intentions via Imagined Intergroup Contact. In: Journal of Experimental Social Psychology 48(1), 437-440. doi: 10.1016/j.jesp.2011.09.008.

Vezzali, L./Stathi, S./Giovannini, D. (2012): Indirect Contact through Book Reading: Improving Adolescents' Attitudes and Behavioral Intentions toward Immigrants. In: Psychology in the Schools 49(2), 148-62. doi: 10.1002/pits.20621.

Waytz, A./Epley, N./Cacioppo, J. T. (2010): Social Cognition Unbound: Insights into Anthropomorphism and Dehumanization. In: Current Directions in Psychological Science 19(1), 58-62. doi: 10.1177/0963721409359302. 
